\title{
Infinitism, finitude and normativity
}

\author{
John Turri
}

Published online: 22 December 2011

(C) Springer Science+Business Media B.V. 2011

\begin{abstract}
I evaluate two new objections to an infinitist account of epistemic justification, and conclude that they fail to raise any new problems for infinitism. The new objections are a refined version of the finite-mind objection, which says infinitism demands more than finite minds can muster, and the normativity objection, which says infinitism entails that we are epistemically blameless in holding all our beliefs. I show how resources deployed in response to the most popular objection to infinitism, the original finite-mind objection, can be redeployed to address the two new objections.
\end{abstract}

Keywords Infinitism - Finite-mind objection · Epistemic normativity · Epistemic justification · Peter Klein · Adam Podlaskowski · Joshua Smith

Peter Klein presents the most carefully articulated version of epistemological infinitism on offer. Klein's infinitist theory of epistemic justification has steadily evolved over the past decade. The basic idea is this. For a proposition $Q$ to be justified for you is for there to be available to you an appropriately structured, infinite series of reasons supporting Q. For you to justifiedly believe $Q$ is for you to have appropriately produced enough of the reasons from that series in order to satisfy the contextually determined standards of justification.

We can state the basic idea more precisely. Where every distinct subscripted ' $R$ ' names a different reason, and good reasons are non-overridden:

Infinitist propositional justification (IPJ): The proposition Q is propositionally justified for you just in case there is available to you at least one infinite

\section{J. Turri $(\bowtie)$}

Philosophy Department, University of Waterloo, 200 University Avenue West,

Waterloo, ON, Candada

e-mail: john.turri@gmail.com 
non-repeating series of propositions (or reasons) such that $R_{1}$ is a good reason to believe $\mathrm{Q}, \mathrm{R}_{2}$ is a good reason to believe $\mathrm{R}_{1}, \mathrm{R}_{3}$ is a good reason to believe $R_{2}, \ldots, R_{m+1}$ is a good reason to believe $R_{m}$, for any arbitrarily high $\mathrm{m}$. (Klein 2005a 135-6; Klein 2007a: 8, 11; compare Klein 2005b: 166).

Infinitist doxastic justification (IDJ): Your belief that $\mathrm{Q}$ is doxastically justified just in case $\mathrm{Q}$ is propositionally justified for you, and you have appropriately provided enough reasons along at least one of the infinite non-repeating series of reasons, in virtue of which $\mathrm{Q}$ is propositionally justified for you, to satisfy the contextually determined standards. ${ }^{1}$

Two controversial but central features of Klein's view are worth noting, even though I set them aside for present purposes. First, it is widely rejected that doxastic justification requires you to actually go through the process of justifying your belief, of defending the belief by articulating your reasons (e.g. Alston 1989; Sosa 1991; Audi 1993; but compare Leite 2004). But Klein contends that doxastic justification does require this. And while his view on this might be contested, here I will set it aside. Second, Klein also says that "pragmatic features" of your context "determine" what is admissible as a "bedrock" reason for you. A bedrock reason is a reason that, once you reach it, you are permitted to stop (Klein 2007a 10-12; Klein 2005b, 170-1). Crucially for the infinitist, it is always possible to properly challenge ad infinitum the contextual standards and thereby the erstwhile bedrock reason, although this never actually happens. This "contextualism," as Klein calls it, is a form of what Keith DeRose has called "subject contextualism," rather than the more popular "attributor contextualism" defended by DeRose, Stewart Cohen and others (see DeRose 2009, Cohen 1999; Cohen 2005). Subject contextualism is very controversial, and Klein's view may also be challenged on this point, but I will also set this aside here.

My aim in this paper is to show how infinitism, and in particular Klein's version of it, can respond to two new objections recently posed by Adam Podlaskowski and Joshua Smith. ${ }^{2}$ Whereas Podlaskowski and Smith grant that "Klein has adequately addressed" the popular finite-mind objection to infinitism, they argue that Klein's view nevertheless faces two related, more serious problems (p. 2). I will argue that the same resources that Klein deploys in response to the original finite-mind objection can be redeployed to handle Podlaskowski and Smith's objections. In response to each new objection, an effective response can be formulated by

\footnotetext{
1 Says Klein $(2007 \mathrm{a}, 10)$ : "The infinitist will take the belief that $\mathrm{p}$ to be doxastically justified for $\mathrm{S}$ just in case S has engaged in providing 'enough' reasons along an endless path of reasons." Notice that Klein says providing the reasons is both necessary and sufficient for doxastic justification. In response to Bergmann (2007), Klein (2007b, 26) indicates he might be willing to add that doxastic justification requires S's belief to be "based on" the justifying reasons. But he also suggests that basing is tantamount to there being "an available reason" that you "cite... as a reason" for your belief, so it remains unclear how this potential revision affects his theory. Some features of Podlaskowski and Smith's discussion do depend on attributing to Klein a specific theory of the epistemic basing relation, but those features are irrelevant to the points I wish to make here, so I'll leave them aside.

2 Podlaskowski and Smith (2009). References to the "online early" version of this article are included parenthetically in the main text. For very different objections to infinitism, see Turri 2009a, b, 2010. Fantl 2003 offers an argument for infinitism, which differs interestingly from Klein's.
} 
appealing to seemingly uncontroversial features of dispositions generally. There is no new problem for infinitism here.

The original finite-mind objection to infinitism is that infinitism entails skepticism, because we have finite minds and so cannot possess an infinite series of reasons, at least for most of the things we take ourselves to be justified in believing. Klein has several responses to this objection, but the one relevant for Podlaskowski and Smith's discussion is the strategy of adverting to what we are disposed to cite as reasons. On this approach, in order for a reason to be available to you, you must be disposed to cite the reason at an appropriate point, where admissible dispositions include second-order dispositions to form the relevant firstorder dispositions to cite the reason at the appropriate point. ${ }^{3}$

Podlaskowski and Smith worry that, for at least many things we take ourselves to be justified in believing, there isn't available to us an appropriate series of reasons. Their worry takes shape in light of two facts. First, infinitism requires an infinite number of reasons: anything less, and there's no justification. Second, infinitism requires the reasons to come in a specific order (compare the definition IPJ above): any other order, and the justification is ruined.

Their finitude objection is that because of our finite nature, we don't actually have all the second-order dispositions to cite all the reasons in the appropriate order, in which case skepticism threatens because the chains of reasons aren't available to us. It seems implausible that we actually have the dispositions, they claim, for two reasons. First, we have no "dispositions to act beyond" our lifetime, whereas "most links in an infinite chain" couldn't be cited in our lifetime, because we're finite. ${ }^{4}$ Second, for any chain of reasons, there will be some point along the way where we're "more likely" to "offer a guess" or "become bored" and stop citing reasons, than to cite the correct reason (pp. 7-8).

I'm calling this the "finitude objection" even though it clearly pertains to more than just finitude. It involves potential performance error as well.

Consider the first aspect of the objection, that is, that most reasons in the infinite chain couldn't be cited in our lifetime. This doesn't show that we lack the dispositions in question. We don't have dispositions to act beyond our lifetime, of course, but infinitism doesn't require this. In general, one can have the disposition to do $\mathrm{A}$ in conditions $\mathrm{C}$, even if $\mathrm{C}$ does not and will not obtain in one's lifetime. For instance, suppose that a cure for AIDS will not, in fact, be found until after I die. Despite that, I'm still disposed to cheer if a cure for AIDS is found. Similarly, the infinitist can say that we also have dispositions to cite the relevant reasons if we were in the relevant circumstances, even though we won't, in fact, ever be in the relevant circumstances.

Now consider the second aspect of the objection, that is, that we're "more likely" to make a mistake than to keep correctly citing the next reason in the chain. This might be true, but it doesn't show that we lack the relevant disposition. It's possible

\footnotetext{
3 As Podlaskowski and Smith put it, "Though one might not presently possess the (first-order) disposition to believe that which may be cited as a reason, one nevertheless [might possess] the second-order disposition to form that belief" (p. 6).

4 And, Podlaskowski and Smith would surely add, because supertasking is not an option for us humans.
} 
to have a disposition to do $\mathrm{A}$ in $\mathrm{C}$, and a disposition to do $\mathrm{B}$ in $\mathrm{C}$, even though one is not disposed to do A \& B in C because, say, A and B are incompatible. Juanita might be somewhat disposed to make Obama her unique top choice, and somewhat disposed to make Clinton her unique top choice, though of course she isn't disposed to make them both her unique top choice. If she's more likely to opt for Clinton, it doesn't follow that she lacked any disposition to opt for Obama. And if she opts for Clinton, it doesn't follow that she lacked any disposition to opt for Obama. Likewise, the infinitist can say, even if it's more likely that at some point you'll fail to correctly cite the next reason in the chain, due to a performance error, it doesn't follow that you lack any disposition to correctly cite the next reason.

Podlaskowski and Smith build on the finitude objection in order to lodge another objection to Klein's view, what I will call the normativity objection. The normativity objection says that Klein's view entails that we are epistemically blameless for all our beliefs. This is an objection because intuitively we're not epistemically blameless for all our beliefs.

On Podlaskowski and Smith's reading, Klein claims that being justified involves responsibility, which makes it a normative notion. But, Podlaskowski and Smith argue, if the finitude objection succeeds, and if a very weak ought-implies-can ('OIC') principle is true, then Klein's view entails that "we are always epistemically blameless" (p. 9). Their weak OIC principle says, "If one ought to form beliefs in a particular way, then it must in principle be possible for such a being to form beliefs in that way" (p. 8). However, building on their finitude objection, they deny that we humans can, even in principle, form beliefs in the way Klein's view requires. So Klein's view entails that all our beliefs are epistemically blameless. But then since at least some of our beliefs are not blameless, they conclude, Klein's view is false.

This argument fails because it depends on the finitude objection which, I have already argued, fails. In addition to what was said above against that objection, consider also the following point, which becomes relevant in light of Podlaskowki and Smith's very weak OIC principle. It doesn't seem impossible in principle for humans to live indefinitely, either because they are immortal souls, or because the gods grant them immortality, or because they are physical animals capable of greater and greater technological innovation, which they could use continually to artificially extend their lives and enhance their minds. Neither does it clearly seem impossible for humans to supertask the citation of their reasons. Supertasking would enable the citation of an infinite number of discrete reasons in a finite interval of time. I grant that these possibilities are far-fetched. But that doesn't spoil the point, because Podlaskowski and Smith's OIC principle is so weak that it makes farfetched possibilities relevant: if such things are possible, then the weak OIC principle doesn't undermine Klein's infinitism.

It might be objected that whether or not you're finite, you can't cite (or be disposed to cite) all the members of an infinite set. At whatever point in citing the members, there will be more left. So Klein's view is saddled with implausible skeptical consequences, in light of the requirements on justification imposed by IPJ. ${ }^{5}$ This objection can be met. It's clearly the case that I' $m$ disposed to say 'two' if

\footnotetext{
5 An objection suggested by Stewart Cohen.
} 
I'm counting by ones and I had just said 'one'. Similarly, I'm disposed to say 'one thousand and one' if I'm counting by ones and I had just said 'one thousand'. The same seems true for any arbitrarily large finite natural number $n$ : I'm disposed to say ' $n+1$ ' if I'm counting by ones and I had just said ' $n$ '. Moreover, if we can have such dispositions regarding the citation of natural numbers, then we can have them regarding the citation of reasons too. But this is precisely what Klein needs in order to meet the objection: it provides a way in which there could be available to you an infinite and non-repeating series of reasons, as per IPJ, in terms of what reasons we are disposed to cite under the relevant conditions.

I conclude that the finitude objection and normativity objections pose no new challenge for infinitism. ${ }^{6}$

\section{References}

Alston, W. (1989). Epistemic justification. Ithaca: Cornell University Press.

Audi, R. (1993). The structure of epistemic justification. Cambridge: Cambridge University Press.

Bergmann, M. (2007). Is Klein an infinitist about doxastic justification? Philos Stud, 134(1), 19-24.

Cohen, S. (1999). Contextualism, skepticism, and the structure of reasons. Philos Perspect, 13, 57-89.

Cohen, S. (2005). Knowledge, speaker and subject. Philos Q, 55(219), 199-212.

DeRose, K. (2009). The case for contextualism: knowledge, skepticism, and context, vol 1. Oxford: Oxford University Press.

Fantl, J. (2003). Modest infinitism. Can J Philos, 33(4), 537-562.

Klein, P. (2005a). Infinitism is the solution to the regress problem. In M. Steup \& E. Sosa (Eds.), Contemporary debates in epistemology. Malden: Blackwell.

Klein, P. (2005b). Infinitism's take on justification, knowledge, certainty, and skepticism. Veritas, 50(4), $153-172$.

Klein, P. (2007a). Human knowledge and the infinite progress of reasoning. Philos Stud, 134(1), 1-17.

Klein, P. (2007b). How to be an infinitist about doxastic justification. Philos Stud, 134(1), 25-29.

Leite, A. (2004). On justifying and being justified. Philos Issues, 14, 219-253.

Podlaskowski, A. C., and Smith, J. A. (2009) Infinitism and epistemic normativity. Synthese. doi: 10.1007/x11229-009-9654-1.

Sosa, E. (1991). Knowledge in perspective. Cambridge: Cambridge University Press.

Turri, J. (2009a). On the regress argument for infinitism. Synthese, 166(1), 157-163.

Turri, J. (2009b). An infinitist account of doxastic justification. Dialectica, 63(2), 209-218.

Turri, J. (2010). Foundationalism for modest infinitists. Can J Philos, 40(2), 275-283.

\footnotetext{
${ }^{6}$ For helpful conversation and feedback, I thank Stewart Cohen, Peter Klein, Adam Podlaskowski, Joshua Smith, and Angelo Turri. This research was supported by the Social Sciences and Humanities Research Council of Canada.
} 